\title{
Treatment of Polyostotic Fibrous Dysplasia of the Thoracic Spine with Intravenous Pamidronate: Result from 9 Months Follow Up
}

\author{
Jongjoo Lee, Hyunchul Shin, Young-Jun Kwon \\ Department of Neurosurgery, Kangbuk Samsung Hospital, Sungkyunkwan University School of Medicine, Seoul, Korea
}

Fibrous dysplasia of the spine is very rarely observed. We reported a case of a 57-year-old woman, who presented with neck and bilateral shoulder pain with histologically confirmed fibrous dysplasia, involving the first and second thoracic vertebrae. Clinical and radiological findings were not specific for fibrous dysplasia. The histological biopsy was required for a confirmed diagnosis. Endocrine and metabolic evaluations are required to rule out diseases such as hyperthyroidism, Cushing syndrome and osteomalacia. Fibrous dyplasia can be managed by appropriate medical and surgical treatments based on the patient's neurological status and symptoms. Our patient was given intravenous pamidronate $60 \mathrm{mg} /$ day for 3 days. After 9 months, her initial symptoms were improved, but computed tomography scan of the thoracic spine showed no change of the lesions.

Key Words: Fibrous dysplasia of bone $\cdot$ Thoracic spine $\cdot$ Pamidronate

\section{INTRODUCTION}

Fibrous dysplasia (FD), originally described by Lichtenstein in $1938^{8)}$ and Jaffe in $1942^{9)}$, is a disorder of bone development of unknown etiology, in which cancellous bone is replaced with fibrous tissue resulting in bone expansion. The disease is often subcategorized based on the number of bones involved. Monostotic lesions involve only one bone, whereas polyostotic involve many bones. The spine is affected in only $7-24 \%$ of cases, and fibrous dysplasia of the spine is very rarely observed without disease elsewhere in the body ${ }^{1,14)}$. Fibrous dysplasia of vertebrae in monostotic form has rarely been reported in the literature ${ }^{2,11,15)}$. Polyostotic fibrous dysplasia involving the spine is relatively common. However, polyostotic form of fibrous dysplasia with isolated thoracic spinal localization has not been reported yet ${ }^{12,18,19}$. We reported a case of a 57 -yearold woman, with a histologically confirmed fibrous dysplasia, involving the T1, T2 vertebrae.

\footnotetext{
- Received: January 24, 2015 • Revised: April 13, 2015

- Accepted: April 21, 2015

Corresponding Author: Hyunchul Shin, MD, PhD

Department of Neurosurgery, Kangbuk Samsung Hospital, Sungkyunkwan University School of Medicine, 29 Saemunan-ro, Jongno-gu, Seoul

110-746, Korea

Tel: +82-2-2001-2158, Fax: +82-2-2001-2157

E-mail: imdr.shin@samsung.com

œThis is an Open Access article distributed under the terms of the Creative

Commons Attribution Non-Commercial License (http://creativecommons.org/ licenses/by-nc/3.0/) which permits unrestricted non-commercial use, distribution, and reproduction in any medium, provided the original work is properly cited.
}

\section{CASE REPORT}

A 57-year-old woman complained of neck pain and bilateral shoulder pain of 20 days duration. She visited a local hospital doctor, and magnetic resonance imaging (MRI) of cervical spine showed spine metastasis. Positron emission tomography scan showed a hypermetabolic second thoracic spine and mild and focal hypermetabolism in the right breast. She was referred to our institution on $13^{\text {th }}$ March, 2014.

On admission, there was no evidence of neurologic deficit. Abnormal skin pigmentation was absent. Physical examination revealed no Spurling or Lhermitte's sign. Enhanced MRI of the cervical spine revealed a metastasis in the vertebral body, both lamina and spinous process of the first thoracic spine, vertebral body, and left lamina of the second thoracic spine (Fig. 1,3). Whole body bone scan revealed a focally active bony lesion in the first thoracic spine and otherwise, no active lesion (Fig. 2). Breast sonography and mammography showed negative findings.

Tumor markers (AFP, CEA, CA 19-9, CA125, CYFRA 21-1, NSE) were normal. Ultrasound guided bone biopsy was performed in the spinous process of the second thoracic spine. Histologic examination revealed irregular thin trabeculae of wooven bone with bland-looking spindle cell stroma, suggestive of fibrous dysplasia (Fig. 4).

Surgical treatment was not performed, due to minor symptoms, no increasing pain, and no neurological symptoms. The patient was given intravenous pamidronate $60 \mathrm{mg} /$ day for 3 
days and discharged. After 6 months, she was admitted our institution, and was given intravenous pamidronate $60 \mathrm{mg} / \mathrm{day}$ for 3 days again. Thoracic computed tomography scan showed no change of fibrous dysplasia involving bodies and posterior elements of the first and second thoracic spine (Fig. 5). However, previous neck pain and bilateral shoulder pain were improved. Three months later, the cervical magnetic resonance imaging scan showed no change of fibrous dysplasia involving bodies and posterior elements of the first and second thoracic spine.

\section{DISCUSSION}

Fibrous dysplasia is a benign intramedullary fibro-osseus lesion characterized by the replacement of bone and marrow with poorly organized spicules of immature bone in fibrous

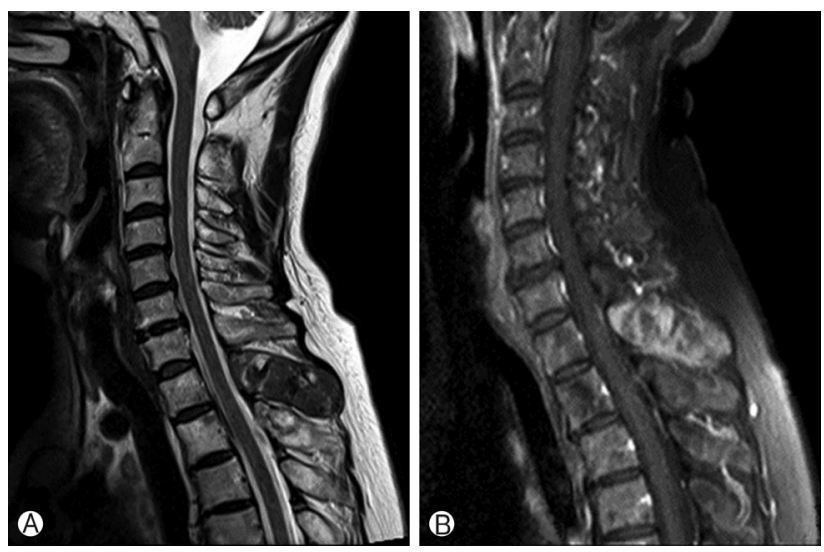

Fig. 1. Cervical MRI image. (A) Sagittal T2-weighted image shows T1, T2 metastatic lesions, in which a hypointense signal replaced the cancellous bone, (B) Enhanced T1-weighted image shows high signal lesion in T1, T2 spinous processes.

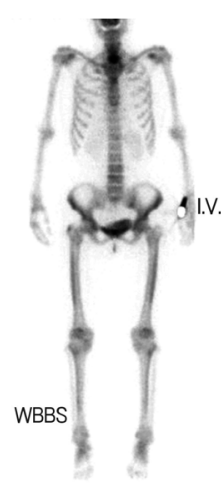

ANTERIOR

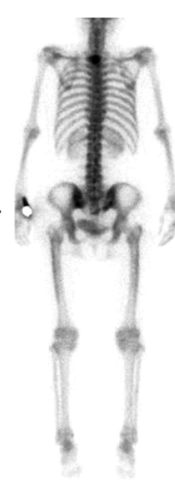

POSTERIOR

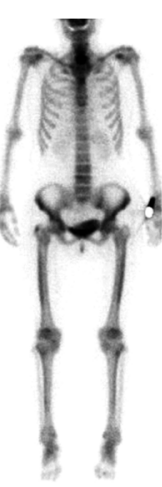

ANTERIOR

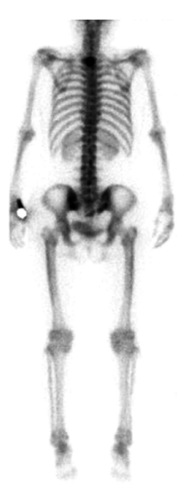

POSTERIOR
Fig. 2. Whole body bone scan shows focal active bony lesion in T1 suggesting bone metastasis and primary bone tumor, and otherwise no active bone or joint lesion. connective tissue ${ }^{8,9)}$.

This clinical entity is divided into 2 types: single-bone involvement (the monostotic type) and multiple-bone involvement (the polyostotic type). Monostotic form is more frequent (75$80 \%)$ than the polystotic form. The polyostotic form has a McCune-Albright syndrome (multiple bone lesions with or without cafe-au-lait spots and with endocrine dysfunction including precocious puberty, hyperthyroidism, acromegaly) and a Mazabraud syndrome (multiple bone lesion with soft tissue mycosomes) ${ }^{1)}$.

Fibrous dysplasia is typically asymptomatic and discovered incidentally. It rarely leads to neurologic deficit. Usually, the common symptom is a localized, painful swelling ${ }^{13)}$. In some
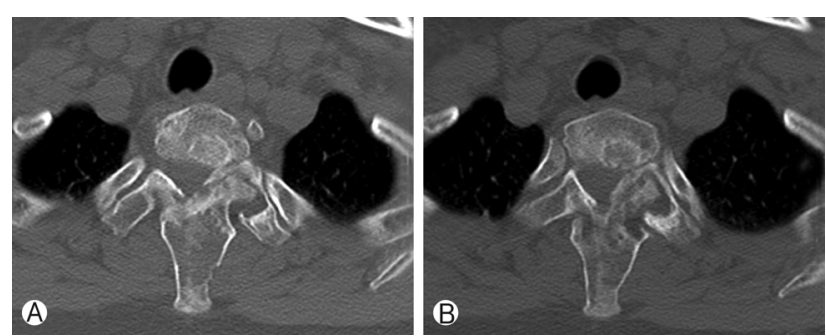

Fig. 3. Computed tomography of cervical spine shows metastatic bone tumor involving bodies and posterior element of $\mathrm{Tl}$ and T2 suggesting osteosarcoma, solitary plasmacytoma and neural foraminal narrowing in the left T1-2 by destructed left facet joint.
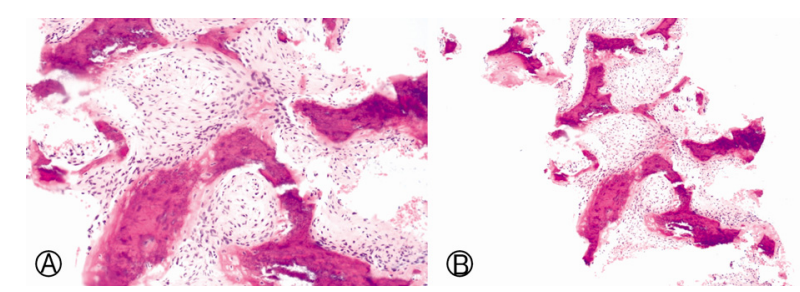

Fig. 4. Histologic examination shows irregular, curvilinear thin trabeculae of woven bone with hypocelluar bland-looking spindle cell stroma components.
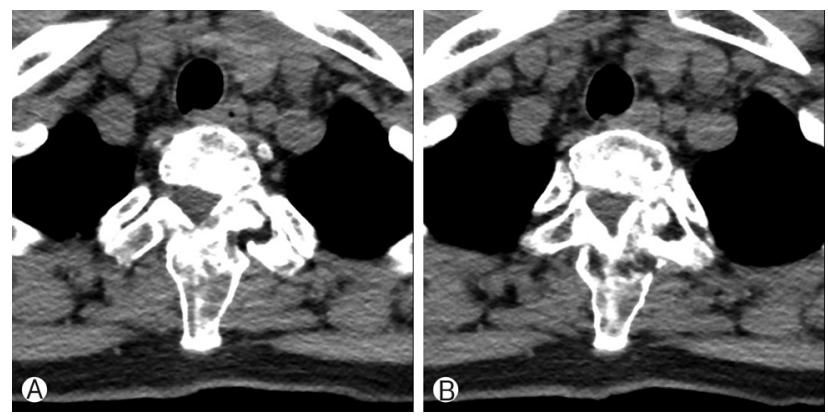

Fig. 5. Computed tomography of cervical spine of cervical spine shows no change of fibrous dysplasia involving bodies and posterior element of $\mathrm{T} 1$ and $\mathrm{T} 2$ spine 6 months after intravenous pamidronate for 3 days. 
cases, it may cause a pathologic fracture ${ }^{2,11,15)}$.

Because of the scarcity of this disorder and symptom, it is hard to know the exact frequency, but fibrous dysplasia represents approximately $2.5 \%$ of all bone neoplasms and $7 \%$ of benign bone neoplasms. Malignant transformation occurs with a frequency of $0.5 \%$ in monostotic form but it may rise to $4 \%$ in the McCune-Albright syndrome ${ }^{1)}$.

The etiology of fibrous dysplasia has been linked to an activating mutation in the GNAS1 gene located at 20q13.213.3 that encodes the alpha subunit of stimulatory Gs protein. Due to this mutation, adenyl cylase stimulation, overproduction of cyclic AMP, and overexpression of the c-fos protein leads to abnormally differentiated osteoblastic cell that overproduce interleukin-6, which causes osteoclast overactivity and osteolysis in the fibrous tissue and bone ${ }^{5,16,20)}$.

The most common involvements of the disease are long bones such as femur, tibia and cranial, facial, ribs and pelvis while vertebral involvement is rare. The spine involvement occurs in $1.4 \%$ to $5.5 \%$ of fibrous dysplasia lesions. Although monostotic fibrous dysplasia occurs more frequently (corresponding to $70 \%$ of cases) than the polyostotic form $(23 \%)^{1)}$, spinal involvement is mostly seen in the polyostotic form and is very unusal in the monostotic variety ${ }^{1,14)}$. There have been a few case reports of monostotic fibrous dysplasia involving only one vertebra. Oba et al. ${ }^{11)}$ managed fibrous dysplasia involving the $10^{\text {th }}$ vertebra alone by tumor resection followed by bone grafting with hydroxyapatite material. Arazi et al. ${ }^{2)}$ treated fibrous dysplasia located in Th6 with a transthoracic approach and used costal graft and interbody fusion after enbloc resection.

Spinal involvement is frequently seen in the polyostotic form, but isolated thoracic spine involvement has not been previously reported. This was the first polyostotic fibrous dysplasia case involving the thoracic spine alone. In the study of Leet et al. "), spinal involvement was observed in $63 \%$ of the cases with accompany lesions in the pelvis, rib or skull by bone scanning. Arantes et al. ${ }^{1)}$ 's report indicated that polyostotic fibrous dysplasia has a vertebral involvement rate of 7-24\%.

An endocrine and metabolic evaluation is necessary after confirmatory diagnosis by histologic examinations.

The reported treatment of fibrous dysplasia in the spine varies widely from surgical resection to biopsy and observation. There have been various options including calcitonin, denosumab, bisphosphonate (pamidronate, zoledronate) and mithramycin and operative treatment including currettage, fixation, fusion, and bone grafting. Each treatment options are available according to patient's symptom and neurologic status.

Surgical indications for fibrous dysplasia include spinal instability and confirming the diagnosis and neurologic deficit. Przybylski et al. ${ }^{15)}$ conducted posterior fusion and instrumenta- tion combined with anterior strut graft and $360^{\circ}$ spinal fusion after resecting the tumor in fibrous dysplasia located in thorax. Their patient had kyphotic deformation and neurological progression. Wu et al. ${ }^{17)}$ treated thoracic fibrous dysplasia by decompression surgery combined with vertebroplasty and posterior fusion.

Some studies reported that the pain and radiologic lesions associated with fibrous dysplasia lesions were successfully treated with bisphosphonates. Liens et al. ${ }^{10)}$ reported 9 patients treated with intravenous pamidronate $(60 \mathrm{mg}$ per day over 3 days every six months), who were followed for 18-48 months. Radiologic changes were seen in 4 patients with cortical thickening, and refilling of osteolytic lesions. Chapurlat et al. ${ }^{6}$ treated 58 patients with fibrous dysplasia using intravenous pamidronate $180 \mathrm{mg}$ every 6 months and reported that intravenous pamidronate improves the radiologic aspect in 50\% patients with fibrous dysplasia. Antiresorptive agents such as biphophonates can be used due to high density of osteoclasts and evidence of bone resorption in fibrous dysplasia lesions. However, Boyce et al. ${ }^{4}$ ) reported that alendronate had effect on reduction in the bone resorption marker but no significant effect on serum osteocalcin, pain or functional parameters. In another study, Boyce et al. ${ }^{3)}$ present the case of a 9-year-old boy with severe fibrous dysplasia who was treated with denosumab. Over 7 months of treatment, the pain was mar-kedly reduced and bone turnover markers were reduced. Randomized control studies and further clinical trials are necessary to establish medical treatment of fibrous dysplasia.

\section{CONCLUSION}

In conclusion, we presented a case of polyostotic fibrous dysplasia involving thoracic spine with symptom of neck pain, bilateral shoulder pain mimicking a metastatic lesion or infectious lesion. Fibrous dysplasia often has vague clinical and radiological findings. Histological biopsy is therefore required. Endocrine and metabolic evaluation should be performed to exclude hyperthyroidism, Cushing syndrome, and osteomalacia. Fibrous dyplasia can be managed by appropriate medical and surgical treatment based on the patient's neurological status and symptoms. We treated the patient with intravenous pamidronate $60 \mathrm{mg} /$ day for 3 days. After 9 months, her initial symptoms were improved, but the computed tomography scan of the thoracic spine showed no change in the lesions.

\section{REFERENCES}

1. Arantes M, Vaz AR, Honavar M, Resende M, Pereira JR: Fibrous dysplasia of the first cervical vertebra. Spine (Phila Pa 
1976) 33:E933-935, 2008

2. Arazi M, Guney O, Ozdemir M, Uluoglu O, Uzum N: Monostotic fibrous dysplasia of the thoracic spine: Clinopathological description and follow up. Case report. J Neurosurg 100:378381, 2004

3. Boyce AM, Chong WH, Yao J, Gafni RI, Kelly MH, Chamberlain $\mathrm{CE}$, et al: Denosumab treatment for fibrous dysplasia. J Bone Miner Res 27:1462-1470, 2012

4. Boyce AM, Kelly MH, Brillante BA, Kushner H, Wientroub $\mathrm{S}$, Riminucci $\mathrm{M}$, et al: A randomized, double blind, placebocontrolled trial of alendronate treatment for fibrous dysplasia of bone. J Clin Endocrinol Metab 99:4133-4140, 2014

5. Candeliere GA, Glorieux FH, Prud'homme J, St-Arnaud R: Increased expression of the c-fos proto-oncogene in bone from patients with fibrous dysplasia. N Engl J Med 332:1546-1551, 1995

6. Chapurlat RD, Hugueny P, Delmas PD, Meunier PJ: Treatment of fibrous dysplasia of bone with intravenous pamidronate: Long-term effectiveness and evaluation of predictors of response to treatment. Bone 35:235-242, 2004

7. Leet AI, Magur E, Lee JS, Wientroub S, Robey PG, Collins MT: Fibrous dysplasia in the spine: Prevalence of lesions and association with scoliosis. J Bone Joint Surg Am 86-A:531-537, 2004

8. Lichtenstein L: Polyostotic fibrous dysplasia. Archives of Surgery 36:874-898, 1938

9. Lichtenstein L, Jaffe HL: Fibrous dysplasia of bone. A condition affecting one, several or many bones, the graver cases of which may present abnormal pigmentation of skin, premature sexual development, hyperthyroidism or still other extraskeletal abnormalities. Arch Pathol 33:777-816, 1942

10. Liens D, Delmas PD, Meunier PJ: Long-term effects of intravenous pamidronate in fibrous dysplasia of bone. Lancet 343: 953-954, 1994
11. Oba M, Nakagami W, Maeda M, Kobayashi K: Symptomatic monostotic fibrous dysplasia of the thoracic spine. Spine (Phila Pa 1976) 23:741-743, 1998

12. Ould Slimane M, Foulongne E, Derrey S, Freger P, Proust F: Polyostotic fibrous dysplasia of the thoracic spine. A case study and review of the literature. Neurochirurgie 55:595-599, 2009

13. Peltier J, Lefranc M, Fichten A, Cordonnier C, Toussaint $\mathrm{P}$, Desenclos C, et al: Odontoid fracture complicating JaffeLichtenstein disease. Case report. J Neurosurg Spine 8:295-299, 2008

14. Proschek D, Orler R, Stauffer E, Heini P: Monostotic fibrous dysplasia of the spine: Report of a case involving a cervical vertebra. Arch Orthop Trauma Surg 127:75-79, 2007

15. Przybylski GJ, Pollack IF, Ward WT: Monostotic fibrous dysplasia of the thoracic spine. A case report. Spine (Phila Pa 1976) 21:860-865, 1996

16. Weinstein LS, Shenker A, Gejman PV, Merino MJ, Friedman E, Spiegel AM: Activating mutations of the stimulatory $G$ protein in the McCune-Albright syndrome. N Engl J Med 325:16881695, 1991

17. Wu FL, Jiang L, Liu C, Yang SM, Wei F, Dang L, et al: Fibrous dysplasia of the mobile spine: Report of 8 cases and review of the literature. Spine (Phila Pa 1976) 38:2016-2022, 2013

18. Wu FL, Liu ZJ, Liu XG, Yang SM, Jiang L, Wei F, et al: Polyostotic fibrous dysplasia involving the thoracic spine with myelopathy: Case report and review of the literature. Spine J 14:e11-15, 2014

19. Yalniz E, Er T, Ozyilmaz F: Fibrous dysplasia of the spine with sarcomatous transformation: A case report and review of the literature. Eur Spine J 4:372-374, 1995

20. Yamamoto T, Ozono K, Kasayama S, Yoh K, Hiroshima K, Takagi M, et al: Increased IL-6-production by cells isolated from the fibrous bone dysplasia tissues in patients with MccuneAlbright syndrome. J Clin Invest 98:30-35, 1996 